\title{
The Effect of Thoracal Paravertebral Block on Seroma Reduction in Breast Surger; a Randomized Controlled Trial
}

\author{
Kuş A. ${ }^{1}$, Yörükoğlu HU. ${ }^{1}$, Aksu C. ${ }^{1}$, Çınar,S²., Cantürk NZ. ${ }^{2}$, Gürkan Y. ${ }^{3}$ \\ 1.Kocaeli University, Department of Anesthesiology and Reanimation \\ 2.Kocaeli University, Department of General Surgery \\ 3.Koç University, Department of Anesthesiology and Reanimation
}

\section{Introduction}

An increasing number of patients are being operated because of breast cancer. Seroma is the most common problem that occurs after surgery that increases morbidity. In addition, seroma is related to postoperative pain which can result in chronic pain. For postoperative pain management, thoracal paravertebral block (TPVB) has

long been considered the gold standard technique. With performing TPVB, sympathetic nerves are also blocked. With this study, we aimed to search the effect of TPVB on seroma reduction in patients who undergo mastectomy and axillary node dissection surgery.

\section{Methods}

Forty ASA I-II female patients aged 18-65, who were scheduled to go under elective unilateral mastectomy and axillary lymph node resection

were included to the study. Patients were randomized into two groups as TPVB and Control group. Ultrasound guided TPVB with $20 \mathrm{~mL}$ 0,25\%

bupivacaine was performed at T1 level preoperatively to the TPVB group patients. All patients were provided with iv patient controlled analgesia device. Seroma formation amounts, morphine consumptions and numeric rating scale

(NRS) scores for pain were recorded 24th hour postoperatively.

\section{Results}

Mean seroma formation at postoperative $24^{\text {th }} \mathrm{h}$ was $112,5 \pm 53,3 \mathrm{~mL}$ in the control group and 74,5 \pm 47,4 $\mathrm{mL}$ in the TPVB group $(p=0,022)$. NRS scores were similar between two groups $(p=0,367)$ at postoperative $24^{\text {th }}$ hour but mean morphine consumption at postoperative $24^{\text {th }} \mathrm{h}$ was $5,6 \pm 4$ in the TPBV group, and 16,6 $\pm 6,9$ in the control group $(p<0,001)$ (Table 1).

Table 2. Amount of seroma formation at the postoperative $24^{\text {th }} \mathrm{h}$

\begin{tabular}{|l|l|l|l|}
\hline & $\begin{array}{l}\text { TPVB group } \\
(\mathrm{n}=20)\end{array}$ & $\begin{array}{l}\text { Control group } \\
(\mathrm{n}=20)\end{array}$ & $P$ \\
\hline Seroma $(\mathrm{mL})$ & $112,5 \pm 53,39$ & $74,5 \pm 47,4$ & $\mathbf{0 , 0 2 2}^{*}$ \\
\hline $\begin{array}{l}\text { Morphine consumption } \\
(\mathrm{mg})\end{array}$ & $5,6 \pm 4$ & $16,6 \pm 6,9$ & $<\mathbf{0 , 0 0 1 *}$ \\
\hline NRS scores & $1 \pm 1,3$ & $0,7 \pm 1$ & 0,367 \\
\hline
\end{tabular}

Data are presented as mean \pm SD

\section{Conclusions}

TPVB reduces the amount of seroma formation while providing effective analgesia in patients who undergo mastectomy and axillary lymph node removal surgery.

\section{Referances}

1. Aitken DR, Minton JP. Complications associated with mastectomy. Surg Clin North Am 1983;63:1331-1352.

2. Pogson C, Adwani A, Ebbs S. Seroma following breast cancer surgery. European J Surg Oncol 2003;29:711-717.

3. Watt-Boolsen S, Nielsen V, Jensen J, Bak S. Postmastectomy seroma. A study of the nature and origin of seroma after mastectomy. Dan Med Bul 1989;36:487-489.

4. Kim HG, Kim K, Seo HG et al. Clinical outcomes of cervical stellate ganglion block in patients with secondary lymphedema: A pilot study. J Korean Acad Rehabil Med 2009:33:297-303.

5. Calì Cassi L, Biffoli F, Francesconi D, Petrella G, Buonomo O. Anesthesia and analgesia in breast surgery: The benefits of peripheral nerve block. Eur Rev Med Pharmacol Sci

2017;21:1341-1345

6. Batra RK, Krishnan K, Agarwal A. Paravertebral block. J Anaesthiol Clin Pharmacol 2011;27:5.

7. Baig S, Moon JY, Shankar H. Review of sympathetic blocks: Anatomy, sonoanatomy, evidence, and techniques. Reg Anesth Pain Med 2017;42:377-391.

8. Park HS. The effect of lumbar sympathetic ganglion block on gynecologic cancer-related lymphedema. Pain Physician 2013;16:345-352.

9. Swedborg I, Arnér S, Meyerson B. New approaches to sympathetic blocks as treatment of postmastectomy lymphedema (report of a successful case). Lymphology 1983;16:157-163.

10. Woodworth GE, Ivie RM, Nelson SM, Walker CM, Maniker RB. Perioperative breast analgesia: A qualitative review of anatomy and regional techniques. Reg Anesth Pain Med 2017;42:609-631.

11. Hida K, Murata H, Ichinomiya T, Inoue H, Sato S, Hara T. Effects of programmed intermittent thoracic paravertebral bolus of levobupivacaine on the spread of sensory block: A randomized, controlled, double-blind study Reg Anesth Pain Med 2019:rapm-2018-100021. 